\title{
Glaucoma is a neuronal disease
}

\begin{abstract}
In glaucoma, disease evolution may not be predicted only from intraocular pressure (IOP) in some patients, as successful IOP-lowering treatment does not always prevent progression. Some patients, such as those with normal-pressure glaucoma, may have more susceptible optic nerves than others. There are several reasons to characterise glaucoma as a neuronal disease, and there is some evidence that IOP is only one of a number of co-factors leading to glaucoma. This paper provides an overview of some of the mechanisms that may be operating at the level of the retinal ganglion cell.
\end{abstract}

Eye (2007) 21, S6-S10; doi:10.1038/sj.eye.6702879

Keywords: glaucoma; neuroprotection; excitotoxicity; retinal ganglion cells; stress proteins

The susceptible optic nerve

Glaucoma is a neuronal disease, and the clinical significance of this can be seen from studies of patients with normal-tension glaucoma. Included in this group are older patients with normal-tension glaucoma; another subset may comprise younger patients with evidence of vasospastic disease often manifested by migraine headaches or Raynaud's phenomenon. What these patients have in common is an apparently susceptible optic nerve. Patients with far advanced damage, regardless of how they arrived at that point, may also be said to have susceptible optic nerves.

For example, the optic disc photography of a patient with progressive normal-tension glaucoma (Figure 1) shows how the same eye changed remarkably over 6 months, particularly in the infero-temporal region of the disc. The visual field shows the sudden appearance, at 6 months, of a very dense superior paracentral scotoma. The contralateral eye had much more damage.
Figure 2 is from the right eye of a 58-year-old patient, who has had a long history of migraine headache and sensitivity to cold in the fingers. The patient developed a narrowing of the superior neuroretinal rim area at low intraocular pressure (IOP 10-12 $\mathrm{mmHg}$ ), and the corresponding visual field defect that can be seen in this figure.

A third example of an apparently susceptible optic nerve is provided by Figure 3, which is from a patient with a damaged and worsening disc. This patient had had a trabeculectomy and low pressures $(8-10 \mathrm{mmHg}$ ) before the first photograph was taken, and continued to get worse despite surgery. Follow-up for this patient was conducted about once a year, revealing repeated disc haemorrhages (one can be seen in the figure) and a progressively narrowing disc rim, both inferiorly and superiorly, despite the most effective treatment possible at the time.

Nouri-Mahdavi et al published a study in $1995^{1}$ that retrospectively considered the long-term functional and structural outcomes of patients treated with trabeculectomy for primary open-angle glaucoma (duration of follow-up 25-112 months). Despite the trabeculectomy, which was the most aggressive treatment at that time, about half the patients, with an average IOP of about $13 \mathrm{mmHg}$, continued to experience disease progression. Damage was defined either as the progression of a visual field defect or worsening of the optic nerve morphology. Again, this suggests that these patients have more susceptible optic nerves.

\section{Multiple causes of disease progression}

It is known that patients with higher IOP are at greater risk of damage to their optic nerve. However, lowering IOP in patients with normal-tension glaucoma can also be helpful. ${ }^{2}$ Thus, even in these patients, IOP-dependent factors may play a role in the development of optic nerve damage. ${ }^{3}$ From this observation, it can be said that both IOP-dependent and IOP-independent factors have a role in the
Correspondence: J Caprioli

E-mail: Caprioli@

jsei.ucla.edu
Stein Eye Institute, Los Angeles (UCLA), LA 

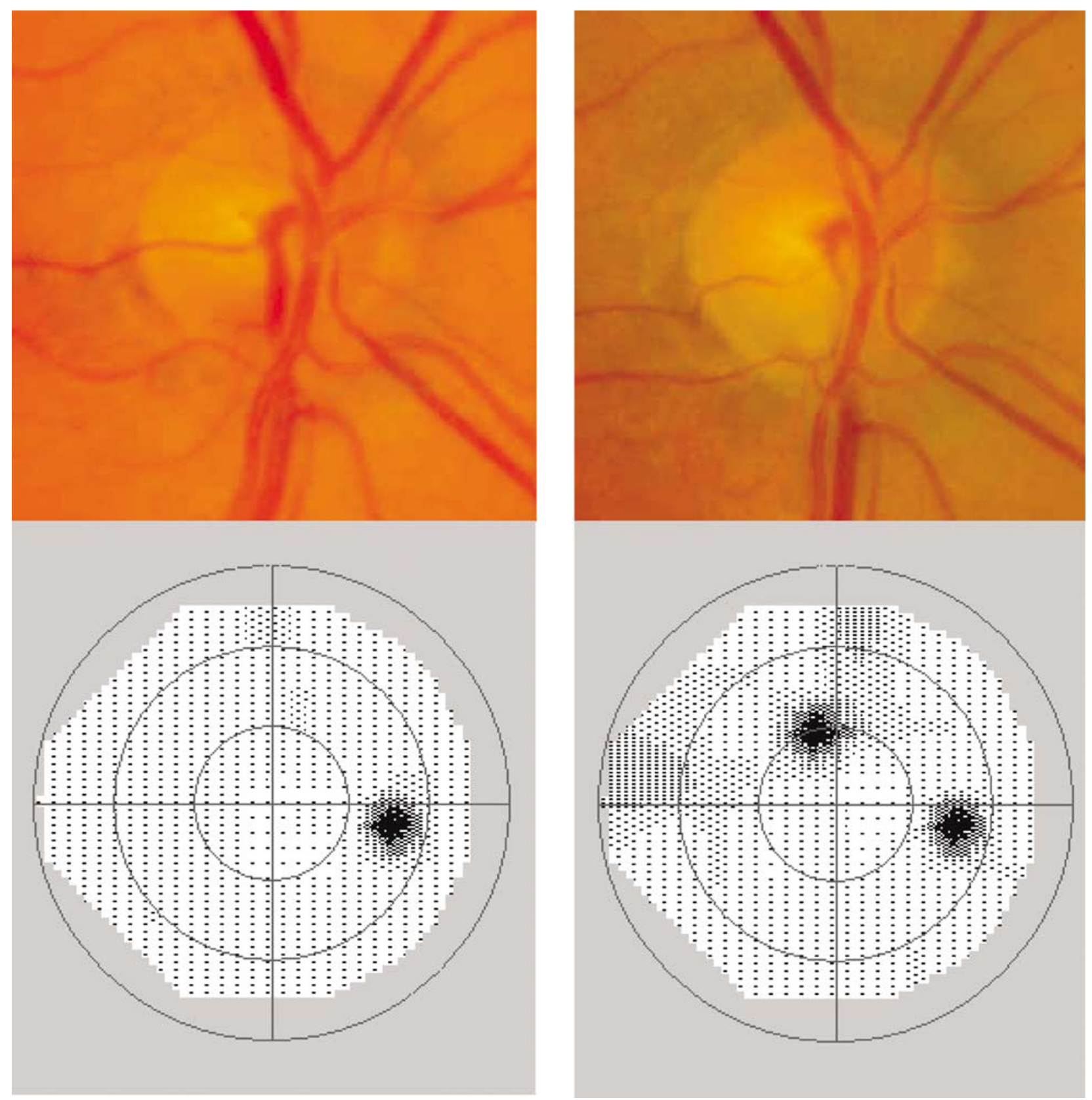

Figure 1 Optic disc photograph and visual field of a patient with progressive normal-tension glaucoma: evolution over time; note the differences between 6 months earlier (left) and 6 months later (right).

development of optic nerve damage, and that their role may be more or less predominant depending on the patient's IOP level. IOP-dependent factors are probably more predominant where high IOPs are required to develop optic nerve damage, whereas IOP-independent factors may have a more predominant role in normal-tension glaucoma. There may also be interactions between IOP-dependent and IOP-independent mechanisms.
Glaucoma is therefore not a single disease with a single cause, but represents conditions with a final common pathway leading to optic nerve damage and visual field loss, which may be reached through various mechanisms (Figure 4). Such mechanisms may be pressure-dependent or pressure-independent and may include genetic predisposing factors, initiating factors such as pressure change, promoting factors such as changes in the laminar structure and sustaining factors of which excitotoxins provide an example. 


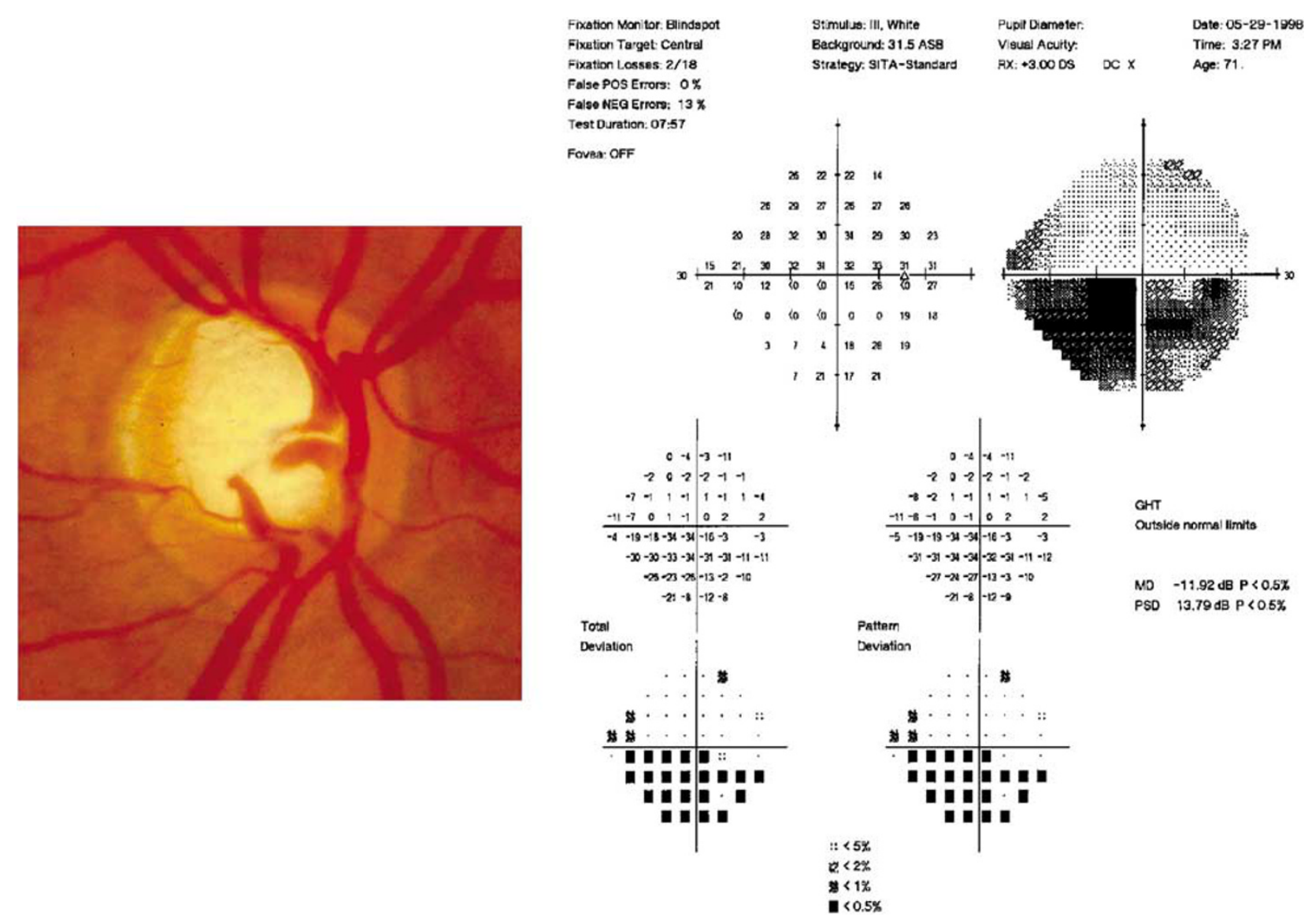

Figure 2 Optic disc photograph and visual field of the right eye of a 58-year-old patient with vasospastic disease.

\section{Possible pressure-independent mechanisms leading to glaucoma}

\section{Excitotoxicity}

It is well established that central nervous system ischaemic damage is mediated by excitotoxicity. Glutamate, the major excitatory neurotransmitter in the brain, exists in high concentrations in the retina, where it is an important neural transmitter. It is thought that either a chronic exposure to moderately elevated levels of glutamate or a hyperactivity of glutamate receptors can trigger cellular processes in neurons that eventually lead to apoptotic-like cell death. ${ }^{4}$ This process is thought to be one of the mechanisms responsible for the apoptosis of retinal ganglion cells (RGCs), which is believed to be biphasic: a first wave of cell degeneration caused by primary injury, followed by secondary degeneration due to excitotoxins released by the degenerating cells. ${ }^{5}$ Cells that survive primary degeneration are believed to be more resistant to injury.

Scotomas that occur in glaucoma are sharply demarcated on the basis of the structure of the optic nerve at the lamina, and not on the basis of their position in the retina. For this pattern to correspond to the proposed mechanism of RGC apoptosis, during the primary degeneration of RGCs, factors that operate at or near the lamina need to be invoked. ${ }^{4}$ During secondary degeneration, IOP-independent factors may be operating, perhaps mediated by excitotoxins in the retina that have been released because of ischaemia or other trauma from primary degeneration. There is some laboratory evidence that seems to support this theory. For example, it has been shown in a mouse model that memantine, ${ }^{4}$ a glutamate blocker, ${ }^{6}$ and timolol, ${ }^{7}$ an IOP-lowering agent, are both neuroprotective.

\section{Proposed secondary mechanisms}

\section{Abnormal glial-neuronal interactions}

Tumour necrosis factor- $\alpha$ induces apoptotic cell death in RGCs and is produced by glia under stress. ${ }^{8}$ 

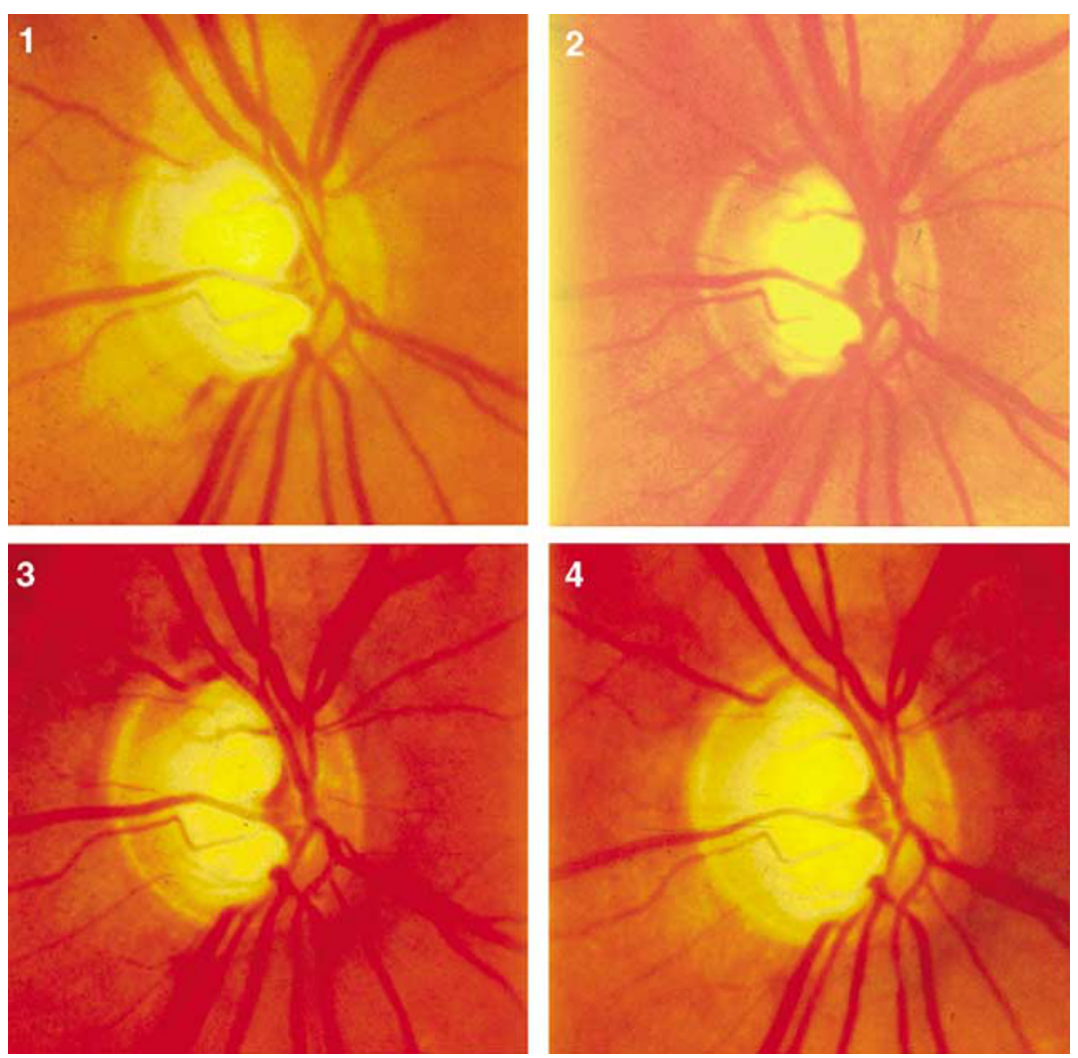

Figure 3 Optic disc photographs of a patient with a damaged and worsening disc, after trabeculectomy, taken at yearly follow-ups.

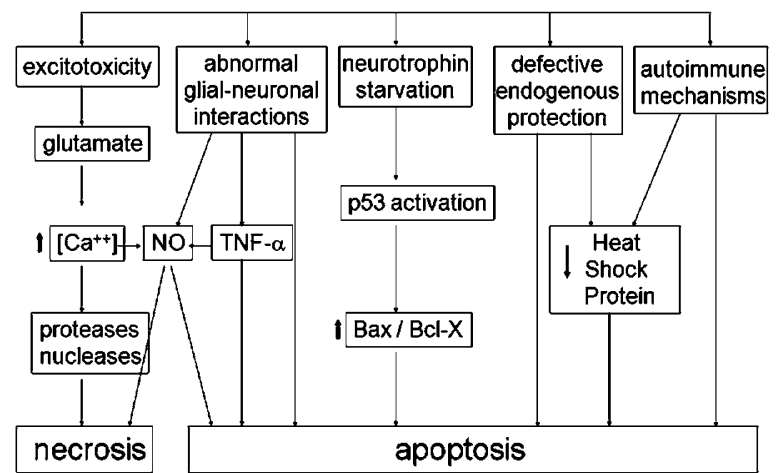

Figure 4 Some possible pressure-independent mechanisms leading to glaucoma.

\section{Neurotrophin starvation}

The neurotrophin starvation theory proposes that retrogradely-flowing neurotrophic factors, to RGC target cells, keep these cells alive. If these sustaining ('growth') factors are removed or blocked, the cells die through apoptosis. ${ }^{9}$ In rat models of optic nerve crush $^{10}$ and chronic ocular hypertension, ${ }^{11}$ it has been possible to protect RGCs from degeneration by systemic treatment with an $\alpha 2$-adrenoreceptor agonist. One possible mechanism is the upregulation of growth factors; ${ }^{12}$ clinical trials have commenced, and the results should help to elucidate the process.

\section{Defective endogenous protection/stress proteins}

Another possibility is that a defect in the RGC makes it more susceptible in some patients.

Formerly, it was believed that a newly synthesised protein, because of thermodynamic considerations, would always fold into a functional conformation. It is now known that proteins can, in fact, fold into non-functional form that the cell has to dispose off through hydrolysis. This is energetically costly for the cell and, to prevent this from happening, smaller chaperone proteins come into play, forcing the newly synthesised proteins, as they roll off the endoplasmic reticulum, to fold into the required conformation. This is called 'assisted assembly'. The protein chaperones are then recycled, making this a very efficient way to synthesise functional proteins. Some of these chaperones are induced in response to cell stress and have been termed 'stress proteins'.

One of the most important inducible stress proteins in neurons is called 'heat-shock protein 72' (Hsp72), with a molecular weight of $72 \mathrm{kDa}$. It is induced in the brain by a variety of stressors and also in rat RGCs. ${ }^{13}$ 
Preconditioning the cells by stressing them with a sublethal insult, inducing stress proteins to form, increases cell tolerance to subsequent injury. For example, when a moderate elevation of IOP was applied in the rat model, after about 8 weeks, the number of RGCs decreased. These rats were then exposed to heat or zinc, which is a mild metabolic stressor, which prevented damage to the ganglion cells from elevated IOP. ${ }^{14}$ Similarly, certain drugs (eg geranyl-geranyl-acetone, GGA, teprenone) that enhance heat-shock protein production (GGA induces transcriptional activation of Hsp72) will protect the cells, and if this enhancement is blocked with a further drug (quercetin), the protective effect is also blocked. ${ }^{15}$

\section{Autoimmune mechanisms}

Autoimmune mechanisms may also be active. A number of auto-antibodies have been reported in glaucoma, including those against rhodopsin, some larger heat-shock proteins and some smaller ones called crystallins (the same protein that exists in the crystalline lens), optic nerve head glycosaminoglycans and neuron-specific enolase. ${ }^{16-20}$

\section{Immune dependence}

Immune dependence has also been demonstrated. Increased pressure causes more damage to RGCs in the immuno-compromised rat compared with the immuno-competent rat. ${ }^{21}$ The relevant mechanisms have been investigated for a number of years.

\section{Conclusions}

Glaucoma is a neuronal disease. We need to develop treatments for glaucoma, with the aim of protecting RGCs, in addition to those that reduce IOP. Pressure reduction will always be an important treatment, but should be enhanced with other neuroprotective treatments in the future.

\section{References}

1 Nouri-Mahdavi K, Hoffman D, Gaasterland D, Caprioli J. Prediction of visual field progression in glaucoma. Invest Ophthalmol Vis Sci 2004; 45(12): 4346-4351.

2 Hoyng PFJ, Kitazawa Y. Medical treatment of normal tension glaucoma. Surv Ophthalmol 2002; 47(Suppl 1): S116-S124.

3 Levin LA. Retinal ganglion cells and neuroprotection for glaucoma. Surv Ophthalmol 2003; 48(Suppl 1): S21-S24.

4 Ankarcrona M, Dypbukt JM, Bonfoco E, Zhivotovsky B, Orrenius S, Lipton SA, Nicotera P. Glutamate-induced neuronal death: a succession of necrosis or apoptosis depending on mitochondrial function. Neuron 1995; 15 961-973.

5 Kaushik S, Pandav SS, Ram J. Neuroprotection in glaucoma. J Postgrad Med 2003; 49(1): 90-95.

6 Petrovic M, Horak M, Sedlacek M, Vyklicky Jr L. Physiology and pathology of NMDA receptors. Prague Med Rep 2005; 106(2): 113-136.

7 Osborne NN, Wood JP, Chidlow G. Invited review: neuroprotective properties of certain beta-adrenoceptor antagonists used for the treatment of glaucoma. J Ocul Pharmacol Ther 2005; 21(3): 175-181.

8 Tezel G, Wax MB. The mechanisms of hsp27 antibodymediated apoptosis in retinal neuronal cells. J Neurosci 2000; 20(10): 3552-3562.

9 Schuettauf F, Quinto K, Naskar R, Zurakowski D. Effects of anti-glaucoma medications on ganglion cell survival: the DBA/2J mouse model. Vision Res 2002; 42(20): 2333-2337.

10 Yoles E, Wheeler LA, Schwartz M. Alpha2-adrenoreceptor agonists are neuroprotective in a rat model of optic nerve degeneration. Vision Res 2002; 42: 2333.

11 WoldeMussie E, Ruiz G, Wijono M, Wheeler LA. Neuroprotection of retinal ganglion cells by brimonidine in rats with laser-induced chronic ocular hypertension. Invest Ophthalmol Vis Sci 1999; 40(1): 65-73. Erratum in: Invest Ophthalmol Vis Sci. Oct 1999; 40(11): 2470.

12 Gao H, Qiao X, Cantor LB, WuDunn D. Up-regulation of brain-derived neurotrophic factor expression by brimonidine in rat retinal ganglion cells. Invest Ophthalmol Vis Sci 2001; 42(12): 2849-2855.

13 Caprioli J, Kitano S, Morgan JE. Hyperthermia and hypoxia increase tolerance of retinal ganglion cells to anoxia and excitotoxicity. Arch Ophthalmol 2002; 120(6): 797-803.

14 Park KH, Cozier F, Ong OC, Caprioli J. Induction of heat shock protein 72 protects retinal ganglion cells in a rat glaucoma model. Invest Ophthalmol Vis Sci 2001; 42(7): 1522-1530.

15 Ishii Y, Kwong JM, Caprioli J. Retinal ganglion cell protection with geranylgeranylacetone, a heat shock protein inducer, in a rat glaucoma model. Invest Ophthalmol Vis Sci 2003; 44: 1982-1992.

16 Romano C, Barrett DA, Li Z, Pestronk A, Wax MB. Anti-rhodopsin antibodies in sera from patients with normal-pressure glaucoma. Invest Ophthalmol Vis Sci 1995; 36(10): 1968-1975. Comment in: Am J Ophthalmol. Feb 1998; 125(2):242-244.

17 Wax MB, Tezel G, Saito I, Gupta RS, Harley JB, Li Z, Romano C. Anti-Ro/SS-A positivity and heat shock protein antibodies in patients with normal-pressure glaucoma. Am J Ophthalmol 1998; 125: 145.

18 Tezel G, Seigel GM, Wax MB. Autoantibodies to small heat shock proteins in glaucoma. Invest Ophthalmol Vis Sci 1998; 39(12): 2277-2287.

19 Tezel G, Edward DP, Wax MB. Serum autoantibodies to optic nerve head glycosaminoglycans in patients with glaucoma. Arch Ophthalmol 1999; 117(7): 917-924.

20 Maruyama I, Ohguro H, Ikeda Y. Retinal ganglion cells recognised by serum autoantibody against gamma-enolase found in glaucoma patients. Invest Ophthalmol Vis Sci 2000; 41(7): 1657-1665.

21 Bakalash S, Kipnis J, Yoles E, Schwartz M. Resistance of retinal ganglion cells to an increase in intraocular pressure is immune-dependent. Invest Ophthalmol Vis Sci 2002; 43(8): 2648-2653. 